\title{
What Does Active Learning Mean For Mathematicians?
}

\section{Benjamin Braun, Priscilla Bremser, Art M. Duval, Elise Lockwood, and Diana White}

Comments are invited at the Notices website: Www.ams.org/journals/notices/

In August 2016 fifteen presidents of member societies of the Conference Board of the Mathematical Sciences (CBMS), an umbrella organization consisting of the American Mathematical Society and sixteen other professional societies in the mathematical sciences, released a statement on active learning [1] with the following call to action:

We call on institutions of higher education, mathematics departments and the mathematics faculty, public policy-makers, and funding agencies to invest time and resources to ensure that effective active learning is incorporated into post-secondary mathematics classrooms.

This call is part of a broad movement to increase the use of active and student-centered teaching techniques across science, technology, engineering, and mathematics (STEM) disciplines. A landmark 2014 meta-analysis published in the Proceedings of the National Academy of Sciences [2] highlighted the efficacy of active learning techniques across STEM disciplines. In mathematics specifically, a comprehensive study of student outcomes for inquiry-based learning [3] has further established that active

Benjamin Braun is associate professor of mathematics and Wimberly and Betty Royster Research Professor at the University of Kentucky, and a member of the Notices board. His e-mail address is benjamin.braun@uky.edu.

Priscilla Bremser is Nathan Beman Professor of Mathematics at Middlebury College. Her e-mail address is bremser@middl ebury. edu.

Art M. Duval is professor of mathematics at the University of Texas at El Paso. His e-mail address is aduva1@utep.edu.

Elise Lockwood is assistant professor at Oregon State University. Her e-mail address is e1 i se. 1ockwood@oregonstate. edu.

Diana White is associate professor at the University of Colorado Denver and director of the National Association of Math Circles at the Mathematical Sciences Research Institute. Her e-mail address is diana. whi te@ucdenver . edu.

For permission to reprint this article, please contact:

reprint-permission@ams . org.

DOI: http://dx.doi.org/10.1090/noti1472 learning methods have a strong positive impact on women and members of other underrepresented groups in mathematics. This movement extends beyond the academic community-for example, at the federal level the White House STEM-for-All initiative [4] includes active learning as one of its three areas of emphasis for the 2017 budget.

While robust support from education researchers, funding agencies, public policymakers, and institutions is a critical component of effective active learning implementation, at the end of the day these techniques and methods are put into practice by mathematics faculty leading classes of students. Thus, mathematics faculty need to be well informed about active learning and related topics. Our goal in this article is to provide a foundation for productive discussions about the use of active learning in postsecondary mathematics. We will focus on topics that frequently arise at the department level, namely: definitions of active learning, examples of active learning techniques and environments used by individual faculty or teams of faculty, things to expect when using active learning methods, and common concerns. An extended discussion of these issues and a substantial bibliography can be found in the six-part series on active learning [5] written by the authors for the AMS blog On Teaching and Learning Mathematics.

\section{What Is Active Learning?}

A frequently asked question is, what is active learning? We base our discussion on the definition given in the CBMS statement [1]: Active learning [refers] to classroom practices that engage students in activities, such as reading, writing, discussion, or problem solving, that promote higher-order thinking. Using a broad definition such as this increases the risk of faculty, administrators, and other stakeholders "talking past" one another, as much is left to the imagination regarding what actually happens with such methods. However, it also acknowledges that active learning can and does involve a wide variety of specific activities in diverse settings, with instructors of varied 


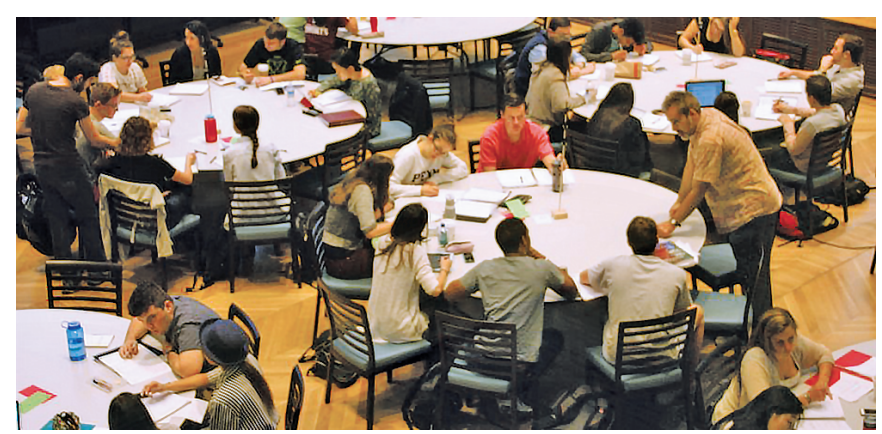

A structured, active, in-class learning (SAIL) class at University of Pennsylvania.

background and experience, and for different kinds of students.

Another approach to defining active learning is more useful in local settings, such as internal department discussions or conversations between department leaders and administrators. In this approach, one focuses discussion on a specific course and defines active learning as a task that students will complete during class time. This helps ensure that everyone in the discussion has a similar vision of what methods are actually being proposed or discussed in the context of explicit course goals and student-learning outcomes.

\section{Examples of Active Learning Techniques and Environments}

In contemporary college and university courses, lecturing remains the dominant teaching technique used by mathematics faculty. While active learning and lecture are sometimes viewed as two diametrically opposed teaching options, this is a misconception, as the following examples illustrate. We begin with examples that primarily involve individual faculty, and we end with examples that require collective buy-in and support from faculty, departments, and institutions.

Think-Pair-Share. One of the simplest examples of an active learning technique suitable for use in lectures is "think-pair-share." In this technique, the instructor provides students with a short task such as doing a computation, completing a step in a proof, generating one or more examples, or forming a hypothesis or conjecture. After providing the students with two to three minutes of time to independently consider the task ("think"), students take two minutes to compare their answers with other students sitting nearby ("pair"). Finally, some or all of the students are asked to share their answers in some manner, either with the groups next to them or with the entire class ("share"). Giving students time to think about and discuss mathematics mid-lecture encourages their active participation in the class. This task has no implications for departments or institutions and serves as an effective comprehension check in which students are able to refocus their attention during a lecture.

Classroom Response Systems (“Clickers"). In addition to think-pair-share, there are many related examples of "classroom voting" systems and techniques that can be used to increase student engagement. These systems are often useful when scaling up think-pair-share and related techniques to large-lecture environments. While some systems are entirely Web and mobile phone based, others require students to rent or purchase a response device. Thus, depending on the choice of system, there can be implications for departments when clicker systems are widely used, and often it is helpful to implement clicker use with a team of faculty rather than individually.

Inverted (or "Flipped") Classes. In an inverted (or "flipped") classroom environment, instructor presentations of basic definitions, examples, proofs, and heuristics are provided to students in videos or in assigned readings that are completed prior to attending class. As a result, class time becomes available for active learning tasks that directly engage students. The type of task that instructors use during this time ranges from using think-pair-shares with complex problems or examples to having students work in small groups on a sequenced activity worksheet with occasional instructor or teaching assistant feedback. The inverted model of teaching has been used as the structure for entire courses, as an occasional event for handling topics that are less amenable to lecture presentations, as the basis for review sessions or problem-solving sessions, and more. Depending on the method used for flipping individual class periods or entire courses, department and/or institutional support (in the form of technical assistance) may often be key ingredients in this model.

Inquiry-Based Learning. One of the most well-known active learning methods in mathematics is inquiry-based learning (IBL). In IBL courses, class time is spent with students working on problem sets individually or in groups, presenting solutions and/or proofs to the class, and receiving feedback from peers and faculty. IBL courses are not based on pure, unguided student discovery; instead, faculty design a series of carefully scaffolded (i.e., sequenced in a structured way) activities, some for individuals, some for pairs, some for small groups, and some for the whole class, including mini-lectures as appropriate. Because faculty using IBL need to develop facility with a range of teaching strategies and need to develop

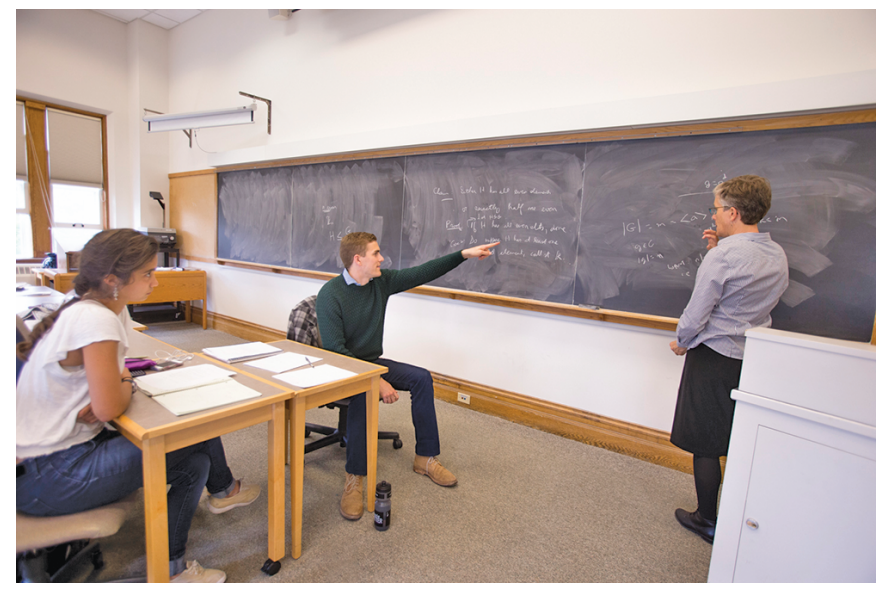

An inquiry-based learning course in abstract algebra at Middlebury College. 


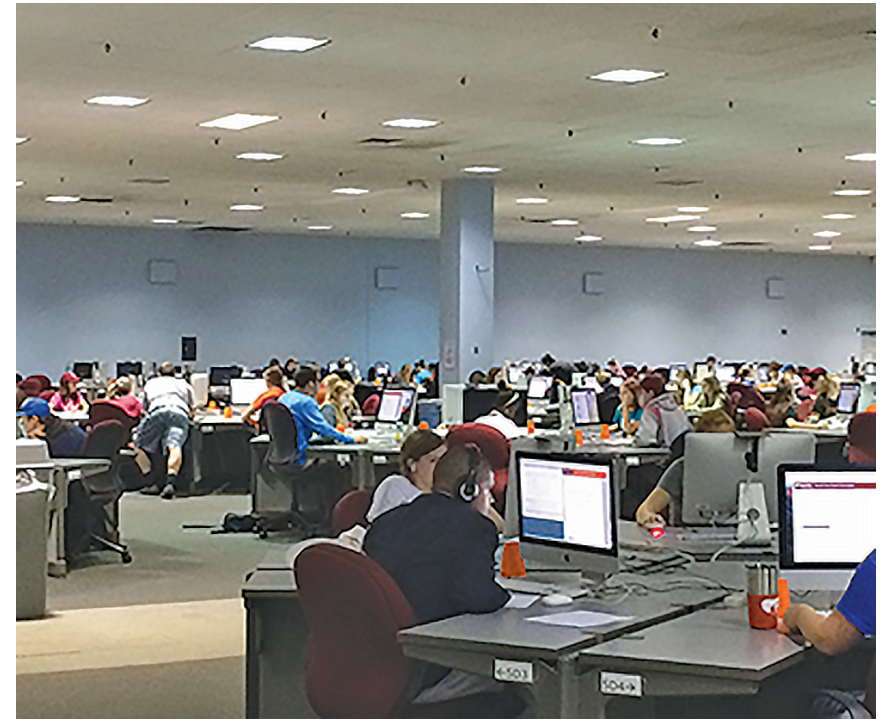

The Math Emporium at Virginia Tech.

familiarity with many "teaching moves" that are not typically used in lecture environments, IBL is a more ambitious active learning environment. There are various opportunities for professional development with IBL, including the workshops offered by the Academy for Inquiry-Based Learning at www. inqui rybasedlearning.org.

Math Emporium. The math emporium model uses a large room filled with computer workstations at which students progress through self-paced online courses. Unlike inverted classes, many emporium models do not include a lecture component at all, and most have been developed to handle remediation issues and low-level courses such as developmental mathematics and college algebra. An emporium usually has tables at which students can work collaboratively and is staffed by a large number of teaching assistants and tutors. Because the work of students is self-paced, students spend most of their time actively engaging with course content through a range of tasks. Because of the significant investment in classroom space and technological resources required, a math emporium is typically launched as a collaborative venture among faculty, departments, and administrators.

Modeling and Computer Laboratories. Modeling is a rich arena for increasing student engagement, one that is often augmented with computer labs. Since the 1990s many mathematics courses have included computer lab activities for exploration using programs such as Mathematica, Maple, MATLAB, and Sage. Recent years have seen a growth in the number of support networks for faculty using lab and modeling components, such as the SIMIODE.org project for differential equations. The 2016 SIAM report Guidelines for Assessment and Instruction in Mathematical Modeling Education provides examples of modeling activities across the undergraduate curriculum that actively engage students and discusses related issues such as assessment. Incorporating modeling and laboratory components into postsecondary courses can be done at many levels, ranging from stand-alone activities in a single class to program-wide implementations supported at the institutional level.

\section{Things to Expect with Active Learning}

Faculty using active learning for the first time need a realistic expectation of what impact these techniques will have. Because there are so many different active learning techniques and because different techniques often influence students in unique ways, it is not always possible to clearly say what will happen when we use a new active learning method. However, there do seem to be a few things faculty can typically expect. Here are five of them.

Expect to gain insights about your students. For many faculty using active learning, these techniques inspire richer discussions with students and provide a window into the reality of students' mathematical experiences. This allows faculty to be more responsive to students' misunderstandings, which in turn causes students to feel more supported in the course, frequently leading to increased engagement. Even in 200-student lectures, where student-faculty dialogue might be heavily moderated by clicker systems, faculty often report that active learning methods provide a clearer sense of what their students understand than with traditional lecture alone.

Expect your students to surprise you. Active learning provides opportunities for faculty-student interaction not present in courses focused on direct instruction.

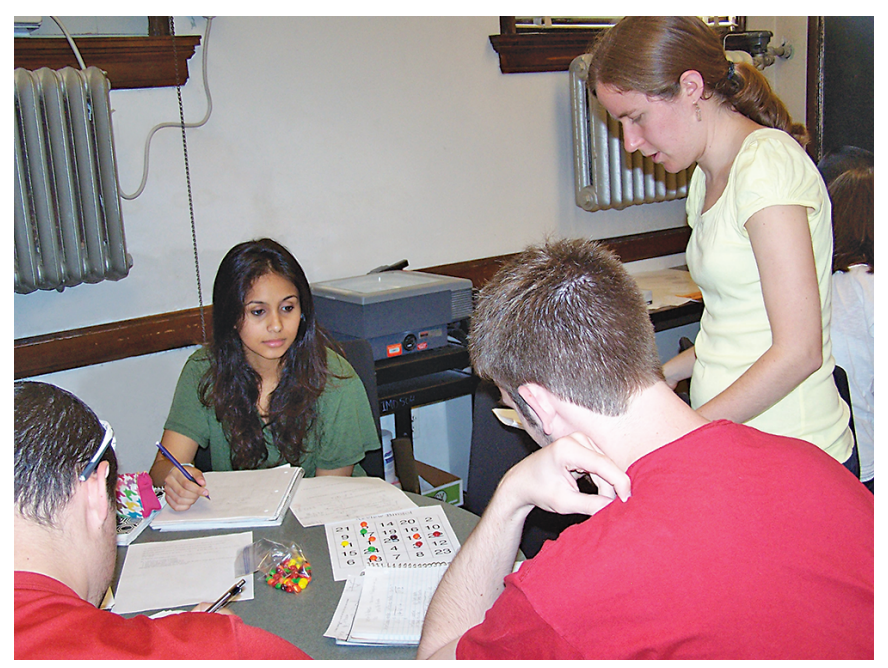

An active learning course from the Merit program at University of Illinois Urbana-Champaign. 
Active learning methods can reach and excite some students who might not typically be vocal or engaged in class-students who are quiet and reserved by nature frequently demonstrate their full potential when provided with the right opportunity. On the other hand, active learning methods can uncover deep misconceptions about mathematics, even from straight-A students, that homework and exams do not reveal. Further, students often respond to active learning tasks with interesting observations and thought-provoking questions, infusing standard courses like calculus with fresh energy.

Expect resistance from some students. For many reasons, it is common for some students to resist active learning methods, especially at the beginning of a course. Some students are not particularly interested in mathematics and do not want to engage at a deeper level. Other students have experienced significant success in traditional mathematics courses and feel threatened by an unfamiliar environment. With all students, instructors need to clearly articulate the value of the active learning methods they use and maintain high expectations for student participation and engagement. Often, students who are initially resistant find themselves surprised at the end of a course by how much they appreciate active learning.

Expect to learn from your mistakes. Much like learning mathematics, learning how to effectively use a new pedagogical technique, especially one of the more complex active learning techniques, involves a process of persistence and error-correction through small failures. Mathematics faculty need to be prepared to start small and develop gradually and consistently. Almost every faculty member the authors have spoken with who uses active learning describes the development of his or her teaching as a sequence of mixed successes and failures. If you are implementing an active learning technique that is new to you, it is often helpful to first discuss with your department chair how teaching in that course will be evaluated for merit reviews. Many colleges have policies to support faculty as they build experience with new teaching techniques, especially if the techniques are evidence based.

Expect long-term impacts. When used in combination with a foundation of good general teaching practices, active learning often has a particularly positive impact on student persistence and sense of belonging in mathematics. This in turn can lead students to be more engaged in their studies and pursue more mathematics over the long term. Because many active learning techniques emphasize communication and collaboration, faculty often report that using these techniques is a catalyst for building strong student communities. These peer networks persist through subsequent courses, contributing to students' experience throughout their mathematical studies. Many of these impacts of active learning become fully visible only after a course ends and thus can be hard to measure or even identify with standard course evaluation instruments.

\section{Common Concerns about Active Learning}

While active learning has many advocates among mathematicians, there are also responsible teachers who have reasonable concerns about active learning methods. We address four of them here.

\section{How will students}

learn the mathematics if we do not clearly tell them everything about it? The historical dominance of the lecture format rests on the belief that learning occurs as a result of transmission of information from instructor to student and that students learn by a process of taking in bits of information that their instructors say or write. Further, because of our passion and love for mathematics, a natural human impulse is for mathematics faculty to tell students about the ways we have come to understand our discipline, to shed light on the subtleties that surround most mathematical ideas, and to explain the fundamental insights of our field. Our common experience, supported by research, demonstrates that learning is not this simple. For example, almost every teacher has experienced telling a student a certain mathematical fact-such as $(a+b)^{2}$ does not equal $a^{2}+b^{2}-$ only to have them demonstrate on a test that they have not learned it. Such experiences suggest that it is not enough for students simply to be told information if we want to produce deep and meaningful learning. Thus, the key is to find an effective balance between direct instruction and active learning, wherein instructors provide guidance through a combination of explanations and active learning tasks.

What if I can't cover the same amount of material? Direct instruction alone can be an efficient way of getting through material. However, the example of students not knowing that $(a+b)^{2}$ does not equal $a^{2}+b^{2}$ should not be far from our minds: lecturing in order to cover more material is not always effective for students. By exclusively considering course content coverage and responding to content coverage with telling, we risk forgetting the many other elements of student learning that active learning addresses, such as the cognitive goals for students outlined in the 2015 MAA CUPM Curriculum Guide [6], including:

- recognize and make mathematically rigorous arguments,

- communicate mathematical ideas clearly and coherently both verbally and in writing,

- work creatively and self-sufficiently,

- assess the correctness of solutions,

- create and explore examples,

- carry out mathematical experiments, and 
- devise and test conjectures.

In addition to the recognition that content topics are not the exclusive subject of coverage, recent research suggests that coverage of material is less important for student persistence and achievement in mathematics than the use of teaching techniques that address these other types of learning goals.

How do I know if I'm doing a good job with my teaching? The crafting of rich lectures contributes to mathematicians' feelings of efficacy in their discipline. There are, however, a number of other ways in which teachers may gain efficacy while balancing traditional lecture with active learning in their classrooms. These include activities such as choosing problems, predicting student reasoning, generating and directing discussion, pushing students for high-quality explanations, asking for questions that extend student knowledge, and obtaining immediate feedback from students regarding what they just learned. Reflecting in this manner shifts the way we measure our own teaching away from the quality of our presentations and toward the quality of the tasks we provide students. Further, many mathematicians who implement active learning report that they have a deeper understanding of student progress and can observe changes in students more clearly than in their previous courses.

I didn't need active learning, why do my students? Although this is changing, many mathematicians have not personally experienced undergraduate teaching environments that include active learning components. Thus, for many mathematicians and graduate students, their first experience with active learning techniques will be as teachers rather than as students. However, we should be careful when comparing our own experiences with those of our students; as Carl Lee [7] has written:

I often engaged in math classes at a high cognitive level merely as a result of a teacher's direct instruction ("lecture"). As a teacher I quickly learned that I engaged few of my students by this process. Not all developed their "mathematical habits of mind" or "mathematical practices" through my in-class lectures and out-ofclass homework (often worked on individually). I now better appreciate the significant role of personal context and informal education in the development of students' capacity.

Research [2], [3] suggests that active learning has a strong positive impact on a wide range of students, not only those who enter our courses ready to independently engage with math at a high cognitive level. That research also suggests that active learning does not harm, and may further benefit, already high-achieving students. Reflecting on our own educations, the authors agree that we would likely have built a firmer mathematical foundation had we experienced more active learning environments and that active learning would have prompted in us an earlier understanding of mathematics as an inquiry-based discipline.

\section{Conclusion}

New instructional techniques cannot be effectively implemented overnight. We must start small and develop gradually and consistently, ideally implementing changes as part of a team that can provide feedback and support. For experienced faculty, this is something we need to do not only for ourselves but with an eye toward training the next generation of mathematicians.

Those of us who work at master's- and doctoral-granting institutions should provide graduate students with training and experience in using active learning techniques, whether as part of recitation duties or in situations where graduate students serve as independent instructors for courses. Given the many demands of graduate school, it is unreasonable to expect that every graduate student in math will emerge as an expert teacher, but we should provide as many opportunities as possible for graduate students to build their skill in using a combination of direct instruction and active learning techniques. For early-career faculty, long-standing professional development programs such as Project NExT provide a valuable service to the mathematical community.

There is a fundamental way in which our training as mathematicians can help us develop as teachers: mathematicians are expert problem solvers. As a community of mathematicians and educators, we are in the process of solving the problem of how best to teach mathematics, and we are working together toward that end. As with all complex real-world problems, the challenge for us is that there is not an exact solution but rather a collection of approximate solutions. Nevertheless, our mathematical training has prepared us as problem solvers to hone our intelligence, our diligence, our spirit of curiosity, and our love of learning in order to develop meaningful and effective ways of teaching. These qualities are directly related to who we are as mathematicians, and they give us hope for success in our continued endeavor of improving mathematics teaching and learning for all.

\section{References}

[1] www.cbmsweb.org/Statements/Active_Learning_State ment.pdf.

[2] S. Freeman, S. Eddy, M. McDonough, M. Smith, N. OKOROAFOR, H. JORDT, and M. WENDEROTH, Active learn ing increases student performance in science, engineering, and mathematics, Proc. Natl. Acad. Sci. USA 111 (23), (2014), 8410-8415. (2016).

[3] M. KOGAN and S. LAURSEN, Assessing long-term effects of in quiry-based learning: A case study from college mathematics. Innov. High. Educ. 39 (2014), 183-199.

[4] https://www.whitehouse.gov/blog/2016/02/11/ stem-a11. (2016).

[5] B. Braun, P. Bremser, A. Duval, E. Lockwood, and D. White, Active Learning in Mathematics, Parts I$V I$ [Web log posts]. Retrieved from blogs.ams.org/ matheducation/tag/activelearning-series-2015 (2015).

[6] C. S. Schumacher and M. J. Siegel, co-chairs, and P. Zorn, editor, 2015 CUPM Curriculum Guide to Majors in the Mathematical Sciences, MAA, Washington, DC, 2015, www.maa.org/programs/faculty 


\section{COMMUNICATION}

-and-departments/curriculum-departmentguidelines-recommendations/cupm.

[7] C. LEE, The Place of Mathematics and the Mathematics of Place [Web log post]. Retrieved from blogs . ams.org/ matheducation/2014/10/01/the-place-of-mathematicsand-the-mathematics-of-place/ (2014).

\section{Photo Credits}

Photo of the SAIL class is courtesy of University of Pennsylvania.

Photo of the classroom at Middlebury College is courtesy of Middlebury College.

Photo of the Math Emporium is courtesy of Virginia Tech Math Emporium.

Photo of the Merit program is courtesy of the Department of Mathematics, University of Illinois at UrbanaChampaign.

\section{Featured Titles from the European Mathematical Society}

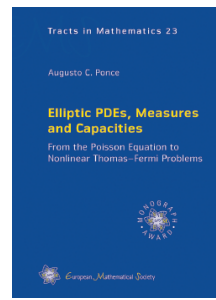

\section{Elliptic PDEs, Measures and Capacities}

From the Poisson Equation to Nonlinear Thomas-Fermi Problems

Augusto C. Ponce,

Université Catholique de Louvain,

Louvain-la-Neuve, Belgium

This book invites the reader on a trip through modern techniques in the frontier of elliptic PDEs and GMT and is addressed to graduate students and researchers with a deep interest in analysis. Most of the chapters can be read independently, and only a basic knowledge of measure theory, functional analysis, and Sobolev spaces is required.

EMS Tracts in Mathematics, Volume 23; 2016; 463 pages; Hardcover; ISBN: 978-3-037/9-140-8; List US\$69; AMS members US\$55.20; Order code EMSTM/23

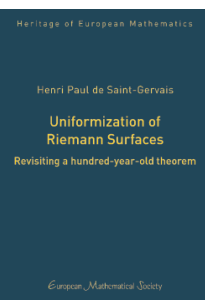

\section{Uniformization of Riemann Surfaces}

Revisiting a

Hundred-Year-Old Theorem

Henri Paul de Saint-Gervais

Translated from the French by Robert Burns, York University, Toronto

In 1907, Paul Koebe and Henri Poincaré almost simultaneously proved the uniformization theorem: Every simply connected Riemann surface is isomorphic to the plane, the open unit disc, or the sphere. The present book offers an overview of the maturation process of this theorem and will be useful to mathematicians wishing to cast a glance back at the history of their discipline. It should also provide graduate students with a non-standard approach to concepts of great importance for modern research.

EMS Heritage of European Mathematics,Volume II; 2016; 512 pages; Hardcover; ISBN: 978-3-03719-145-3; List US\$83; AMS members US\$66.40; Order code EMSHEM/II

Publications of the European Mathematical Society (EMS). Distributed within the Americas by the American Mathematical Society.

View all of the titles that we have to offer at bookstore.ams.org.

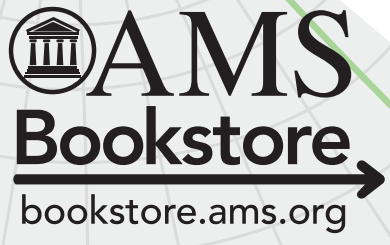

